\title{
ATE Scale to Assess Attitudes towards Euthanasia among Health Professionals in Pokhara, Nepal
}

\section{Parajuli SR ${ }^{1}$, Gautam R ${ }^{2}$, Timsinha $S^{1}$, Subedi A ${ }^{3}$, Pokhrel $\mathbf{S}^{4}$}

\author{
${ }^{1}$ Department of Forensic Medicine, Manipal Teaching Hospital, Pokhara, Nepal \\ ${ }^{2} \mathrm{WHO}$, Nepal \\ ${ }^{3}$ Department of Psychiatry, Manipal Teaching Hospital, Pokhara, Nepal \\ ${ }^{4}$ Department of Physiology, Birat Medical College, Biratnagar, Nepal
}

Received: February 16, 2021

Accepted: April 15, 2021

Published: April 30, 2021

Cite this paper:

Parajuli SR, Gautam R, Timsinha S, Subedi A, Pokhrel S. ATE Scale to Assess Attitudes towards Euthanasia among Health Professionals in Pokhara, Nepal. Nepal Journal of Medical Sciences 2021;6(1):14-19.http:// dx.doi.org/10.3126/njms.v6i1.36726

\begin{abstract}
Introduction: Most people want to live up to old age with no pain and sufferings. This study is meant to know the opinion of doctors and nursing professionals regarding euthanasia which is an important component for practising euthanasia in Nepal, which is a debated topic in the whole world and Nepal is no exception.
\end{abstract}

Methods: A descriptive study design was used to conduct this study. ATE scale was used which includes ten questionnaires.

Results: The ATE scale used in this study showed to have internal consistency, with Cronbach alpha at 0.736 . Men were found to be more supportive of Euthanasia.

Conclusion: Overall, this study suggests that health professionals from Pokhara have a positive attitude towards Euthanasia with patients request taken as more important.

Keywords: Attitude; Euthanasia; Scale

\section{INTRODUCTION}

Most people want to live up to old age with no pain and sufferings. Sadly, this is not the truth and many ends with an endless struggle for painful disease. ${ }^{1}$ The term euthanasia comes from the Greek word, which means "good death," "peaceful death," or "death without

Correspondence to:Dr Sudhir Raman Parajuli Department of Forensic Medicine Manipal Teaching Hospital, Pokhara, Nepal Email: sudhir.parajuli@manipal.edu.np suffering". ${ }^{2}$ Euthanasia is the practice of painlessly putting to death people who have incurable, painful or distressing diseases or disabil- 
ities. $^{3}$ Recently, on the 7th of March 2018, the Supreme Court of our neighbouring country, India legalized passive euthanasia employing the withdrawal of life support to patients in a permanent vegetative state. ${ }^{4}$ Supreme court of Nepal has also tried to consult amici curiae on mercy killing. ${ }^{5}$ Inevitably, it is acts of commission on the part of the doctor that can provide the best possible death, which is the moral objective of euthanasia. The ethical concerns for doctors regarding euthanasia and assisted suicide preparedness will be issues in the coming future. ${ }^{6}$ In the developed world, ethical discussions on 'micro ethics' like cloning and euthanasia centres are established but underdeveloped countries like Nepal are still lagging to deal with the basic questions of ethical professional practice. As health professionals are responsible for practising euthanasia, their attitudes of them play a great role. ${ }^{7}$

There are two scales described in literature ATE (Attitudes Towards Euthanasia) scale and EAS (Euthanasia Attitude Scale) to measure attitude. However, we chose ATE scale as it was found to be more reliable and valid and established Cronbach's alpha as per Wasserman, J. Cronbach's alphas for the EAS and the ATE scale were 0.88 and 0.90 , respectively. ${ }^{8}$

This study is meant to know the opinion of doctors and nursing professionals regarding euthanasia which is an important component for practising euthanasia in Nepal, which is a debated topic in the whole world and Nepal is no exception.

\section{METHODS}

A descriptive study design was used to conduct this study. Non-probability sampling technique was employed. The sample consisted of health personnel, both- doctor \& nurses who were registered either in Nepal Medical Council or Nepal Nursing Council respectively, working in Pokhara in different institutions. Proforma with a set of demographic variables and questionnaires was provided to the individuals and was collected. Informed written consent was taken from all the sub- jects. ATE scale was used which includes ten questionnaires. Likert five-point scale was used to represent attitudes towards euthanasia ranging from strongly agree to strongly disagree with a higher number on strongly agree as per the Wassermann's. ${ }^{9}$ Three extra questions were also kept for other information regarding health, the impact of religion and fear of death. The data was entered and coded in Microsoft Excel and analyzed in SPSS version 22.

\section{RESULTS}

Among 94 participants, 44 were males and 50 were females (Figure 1). The mean age (SD) of the participants was 29.2(5.3) years. Among the participants $52.1 \%$ were unmarried and $47.9 \%$ were married. The majority of the participants were Hindu (78\%) followed by Buddhist (15\%) (Figure 2). Most of the participants have median of two years of experience in their profession with a range of a minimum of 1 year to maximum of 11 years.

Figure 1: Number of participants according to gender and profession

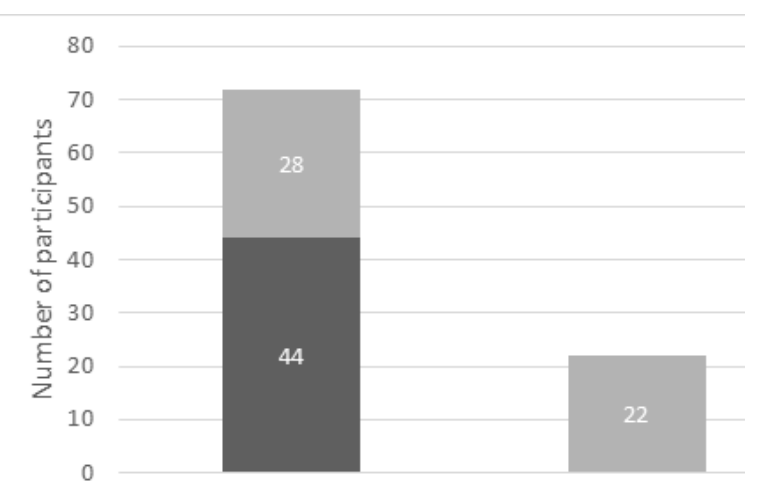

Figure 2: Religion followed by participants

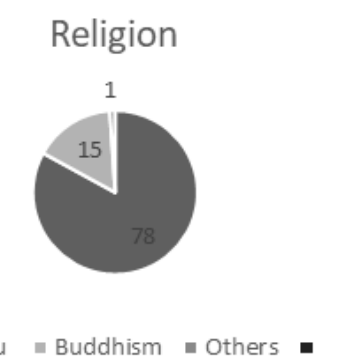

Sixty percent of the participants said they were afraid of death, whereas $16 \%$ had no 
fear of death and $4 \%$ were undecided. Almost $50 \%$ of our participants had a neutral impact by religious belief and almost all were in good health.

The ATE scale used in this study showed to have internal consistency, with Cronbach alpha at 0.736 . The Cronbach alpha if item deleted, ranged from 0.675 to 0.802 . A factor analysis using maximum likelihood extraction with Varimax rotation identified 2 factors with eigenvalues of 4.33 and 1.35 , respectively. These 2 factors explain $56.86 \%$ of the total variance. Factor 1 comprises items 1, 3, 8 , and 10; all the 4 items are of the patient's request dimension. Also, items 2,4,5 and 7 are included in factor 1 but are weekly loaded. Factor 2 comprises items referring to the doctor's authority, items $2,4,5,7$, and the two reverse-coded questions, items 6 and 9. The 2 reverse coded items (6 and 9) loaded weakly on the second factor, which likely reflects the fact that while they refer to the physician as the actor, they do not explicitly frame the physician as the decision-maker (i.e., they do not refer to what the physician believes is the right course of action but only to the physician as performing an action)(Table 1 ).

Table 1: Factor Loadings of the ATE scale

\begin{tabular}{|ccr|} 
& \multicolumn{3}{c}{ Factor } \\
Item & $\mathbf{1}$ & $\mathbf{2}$ \\
\hline
\end{tabular}

3. If a patient in severe 0.765

pain requests it, a doctor should prescribe that patient enough medicine to end their life. (SP/PR/ ACTIVE)

10. If a dying patient 0.759

requests it, a doctor should remove their life support and allow them to die. (NR / PR / WITHDRAW)
1. If a patient in severe 0.724

pain requests it, a doctor should remove life support and allow that patient to die. (SP/PR/ WITHDRAW)

8. If a dying patient 0.711 requests it, a doctor should prescribe enough medicine to end their life. (NR/PR/ACTIVE)

4. It is okay for a doctor $0.621 \quad 0.418$ to remove life support and let a patient die if the doctor does not believe the patient will recover. (NR DA/WITHDRAW)

2. It is okay for a doctor $0.596 \quad 0.488$ to administer enough medicine to end a patient's life if the doctor does not believe that they will recover. (NR/DA/ ACTIVE)

6. Even if a doctor does $-0.782$ not think that a patient will recover, it would be wrong for the doctor to end the life of a patient. * (NR)

9. Even if a doctor knows that a patient is in severe, uncontrollable pain, it would be wrong for the doctor to end the life of that patient. ${ }^{*}(\mathrm{SP})$

7. It is okay for a doctor $0.501 \quad 0.63$ to remove a patient's life support and let them die if the doctor thinks that the patient's pain is too severe. (SP/DA/ WITHDRAW) 


5. It is okay for a doctor 0.475
to administer enough
medicine to a suffering
patient to end that
patient's life if the doctor
thinks that the patient's
pain is too severe. (SP/
DA/ACTIVE)

Abbreviations: SP, severe pain; NR, no recovery; PR, patient requests; DA, doctor's authority; ACTIVE, active termination of the patient's life; WITHDRAW, withdrawing treatment; ATE, attitude toward euthanasia.

Note: ${ }^{*}$ indicates reversed item.

An independent sample t-test was conducted to see the association between gender, marital status, and years of practice with ATE score. It was seen that there was an association between gender and ATE score. Men were found to be more supportive of Euthanasia (score= $3.07, \mathrm{SD}=0.61$ ) compared to female (score $=$ $2.58, \mathrm{SD}=0.51)$ and this was found to be statistically significant $(\mathrm{p}<0.001)$. However, there was no significant association between the marital status and years of practice (Table 2). A Pearson correlation was done to see if there was any association between increasing age and ATE score. However, it was found to be not significant $(\mathrm{r}=.167, \mathrm{p}=0.10)$.

Table 2: Association of sociodemographic characteristics with ATE score

\begin{tabular}{lcc}
\multicolumn{1}{c}{ Category } & Mean \pm SD & p-value \\
Gender & & \\
Male & $3.07 \pm 0.61$ & $\mathbf{< 0 . 0 0 1}$ \\
Female & $2.58 \pm 0.51$ & \\
Marital Status & & \\
Married & $2.87 \pm 0.52$ & 0.399 \\
Unmarried & $2.76 \pm 0.69$ & \\
Year of Practice & & \\
$\leq 2$ years & $2.73 \pm 0.61$ & 0.426 \\
$>2$ years & $2.91 \pm 0.60$ & \\
\hline
\end{tabular}

\section{DISCUSSION}

The findings from this study suggest that doctors and nurses have a positive attitude towards euthanasia with patient request showing a higher correlation which is found to be consistent with the study done by Maria Therese A et al. It concluded that health personnel had a positive attitude towards euthanasia in certain circumstances for terminally ill clients with unbearable pain. ${ }^{1}$ Similarly the study done in Belgium among nurses showed broad support for euthanasia for terminally ill patients and their involvement in consultancy in case of euthanasia requests. ${ }^{10}$ But the study conducted by Yun YH et al. in 2018 among physicians had a more negative attitude towards the active ending of life compared to other groups which included the general population, cancer patients and family caregivers. ${ }^{11}$ Abbas $S$ et al. study among Pakistani doctors also showed a minority of them supporting euthanasia and they belonged to a younger age group. ${ }^{12}$ Aghababaei $\mathrm{N}$ et al. study also showed a low rate of acceptance of the end of life decisions with a majority against euthanasia. ${ }^{13}$

Our study used ATE scale and was found to be valid and was consistent with other studies which measured Cronbach's alpha and were within a valid range of more than 0.70 . 9,13,14

Most of the participants of our research were in their 30s, whereas other studies had different mean age group of 21 and 25-35years. ${ }^{1,8,15}$ Age was not associated with attitudes towards euthanasia and its influence in most other studies was also found to be inconsistent. ${ }^{11}$

Males were found to be more supportive of euthanasia which was similar with the Pakistani male doctors. ${ }^{12}$

We included health professional to know the attitude towards euthanasia as we thought them as one of the important direct stakeholders in this matter. Similarly, the studies conducted by Maria Therese A et al. ${ }^{1}$ and Fernández-Martínez E et al. ${ }^{14}$ and Yun YH et al. ${ }^{11}$ and many other authors also included health professionals whereas many other au- 
thors have conducted studies on medical and nursing students. ${ }^{2,8,9,12,14-18}$

Religion, as well as religious belief, did not show any role in attitude towards euthanasia on our sample. Nepal, where most people are from Hinduism and Buddhism, so the correlation with other religions was not possible. This study showed consistency with the NHS doctors where no association existed between a doctor practising active euthanasia and holding a religious belief. ${ }^{17}$ The religion of the doctors did not appear to be a determining factor in Pakistani doctors too as shown by the study conducted by Abbas $S$ et al. ${ }^{12}$ However, the majority of Muslim nurses in Iran were found to have negative attitudes to euthanasia which we could not compare as we didn't have any Muslim population. ${ }^{16}$

Globally, only a few countries have legislation with discrete and unambiguous guidelines on euthanasia, and we are one with no laws or any kind of guidelines. ${ }^{19}$ The law on India regarding euthanasia had now created a buzz in Nepal too. Further research is hence needed to conduct in more participants who are believed to be the important stakeholders of euthanasia to know more regarding this as our study lacks to include them.

\section{CONCLUSION}

Overall, this study suggests that health professionals from Pokhara have a positive attitude towards euthanasia with patients request taken as more important. ATE scale can be used as an instrument to measure attitudes towards euthanasia. It is the need of an hour to discuss more euthanasia and advocate through different media.

\section{CONFLICT OF INTEREST}

None

\section{SOURCES OF FUNDING}

None

\section{REFERENCES}

1. Therese MA, Rukumani J, Mano PP. A study to assess the level of attitude towards euthanasia among health personnel. J Heal Allied Sci NU. 2014 Dec 1;4(4):18-22. Available from: https:// pdfs.semanticscholar.org/372e/6620e 5cbef94f27a6e06aff71914959573c4. pdf\#page=19 [Accessed 1st March 2021]

2. Hosseinzadeh K, Rafiei H. Nursing Student Attitudes toward Euthanasia: A Cross-Sectional Study. Nurs Ethics. 2019;26:496-503. https://doi. org/10.1177/0969733017718393

3. Dr. Parikh C. (2006). 6th Edition, Page 1.55. Ne Delhi, Publishers \& Distributors. 6th ed. Parikh's Textbook of Medical Jurisprudences, Forensic Medicine and Toxicology. CBS; 2006. 1.55.

4. Zeenat Saberin. India's Supreme Court allows "passive euthanasia." Al Jazeera Media Network [Internet]. 2018; Available from: https://www.aljazeera.com/ news/2018/03/india-supreme-courtpassive-euthanasia-180309064508560. html. [Accessed 20th March 2021]

5. Nepal's supreme court to consult amici curiae on "mercy killing." The Himalayan Times. 2017. Available from: https:// thehimalayantimes.com/nepal/nepalsupreme-court-consult-amici-curiaeeuthanasia [Accessed 14th November 2020]

6. Adhikari RK. Ethics and Nepalese doctors. JNMA. 2000;39:II-IV. https://doi. org/10.31729/jnma.763

7. Chataut B. unveiling the debate on euthanasia. Nepal Public Health foundation. 2015. Available from; https:// www.nphfoundation.org/wp-content/ uploads/2017/09/4th-final-6th-lectureseries.pdf [Accessed 20th March 2021]

8. Aghababaei N, Farahani H, Hatami J. Euthanasia attitude; A comparison of two scales. $J$ Med Ethics Hist Med. 2011;4(9):2-7. Available from: https:// www.ncbi.nlm.nih.gov/pmc/articles/ PMC3713934/[Accessed 21st March 
2021]

9. Wasserman J, Clair JM, Ritchey FJ. A scale to assess attitudes toward Euthanasia. Omega $J$ Death Dying. 2005;51(3):229-37. https://doi. org/10.2190/FGHE-YXHX-QJEAMTM0

10. Inghelbrecht E, Bilsen J, Mortier F, Deliens L. Attitudes of nurses towards euthanasia and towards their role in euthanasia: A nationwide study in Flanders, Belgium. Int $J$ Nurs Stud. 2009;46(9):1209-18. https://doi. org/10.1016/j.ijnurstu.2009.02.009

11. Yun $\mathrm{YH}, \mathrm{Kim} \mathrm{KN}$, Sim JA, Yoo SH, Kim M, Kim YA et al. Comparison of attitudes towards five end-of-life care interventions (active pain control, withdrawal of futile life-sustaining treatment, passive euthanasia, active euthanasia and physician-assisted suicide): a multicentred cross-sectional survey of Korea. BMJ Open. 2018;8(9):e020519. https:// doi.org/10.1136/bmjopen-2017-020519

12. Abbas S, Abbas Z, Macaden S. Attitudes towards euthanasia and physicianassisted suicide among Pakistani and Indian doctors: A survey. Indian J Palliat Care. 2008;14(2):71. https://doi. org/10.4103/0973-1075.45448

13. Aghababaei N, Wasserman JA. Attitude Toward Euthanasia Scale: Psychometric Properties and Relations With Religious Orientation, Personality, and Life Satisfaction. Am J Hosp Palliat Med. 2013;30(8):781-5. https://doi. org/10.1177/1049909112472721

14. Fernández-Martínez E, FernándezMuñoz JJ, Romero-Blanco C, ParraFernández ML, Onieva-Zafra MD. Spanish version of the attitude towards euthanasia scale. Int J Environ Res Public Health. 2020;17(11):1-8. https://doi. org/10.3390/ijerph17113855

15. Senmar M, Yousefi F, Alipour R, Elikaei N, Keshavarz M, Rafiei H. Iranian medical student's attitude towards euthana- sia. Mintage journal of Pharmaceutical \& Medical Sciences. 2017;6(4):9-11. Available from: http://eprints.qums. ac.ir/7261/1/senmar.pdf [Accesses 15th November 2020]

16. Naseh L, Rafiei H, Heidari M. Nurses' attitudes towards euthanasia: a cross-sectional study in Iran. Int $J$ Palliat Nurs. 2015;21(1):43-8. https://doi. org/10.12968/ijpn.2015.21.1.43

17. Ward BJ, Tate PA. Attitudes among NHS doctors to requests for euthanasia. BMJ. 1994;308(6940):1332-4. https://doi. org/10.1136/bmj.308.6940.1332

18. Thirmal C, Dahman Y. Different physical and chemical pretreatments of wheat straw for enhanced biobutanol production in simultaneous saccharification and fermentation. Int $J$ Energy Environ. 2011;2(4):615-26. Available from: http://www.ijee.ieefoundation.org/vol2/ issue4/IJEE 03 v2n4.pdf [Accessed 25th March 2021]

19. Shekhawat RS, Kanchan T, Setia P, Atreya A, Krishan K. Euthanasia: Global Scenario and Its Status in India. Sci Eng Ethics. 2018;24(2):349-60. https://doi. org/10.1007/s11948-017-9946-7 